\title{
Layer-by-Layer Assembly for Graphene-Based Multilayer Nanocomposites: The Field Manual
}

Eungjin Ahn, ${ }^{1}$ Taemin Lee, ${ }^{1}$ Minsu Gu, ${ }^{1}$ Minju Park, ${ }^{1}$ Sa Hoon Min, ${ }^{1}$ and Byeong-Su Kim ${ }^{1,2 *}$

${ }^{1}$ Department of Energy Engineering and ${ }^{2}$ Department of Chemistry, Low Dimensional Carbon Materials Center, Ulsan National Institute of Science and Technology (UNIST), Ulsan 44919, Korea

E-mail: bskim19@unist.ac.kr

Table of Contents

I. Characterization of GO sheets

II. Experimental methods

A. Preparation of aqueous PANi suspension

B. Preparation and DMAP functionalization of Au NPs

III. Calculation of relative charge density of $\mathrm{GO}(-)$ in $\mathrm{pH} \mathrm{3,} \mathrm{7,} \mathrm{and} 11$ conditions

IV. Materials and equipment lists
A. Materials
B. Equipment 


\section{Characterization of GO sheets}

a)

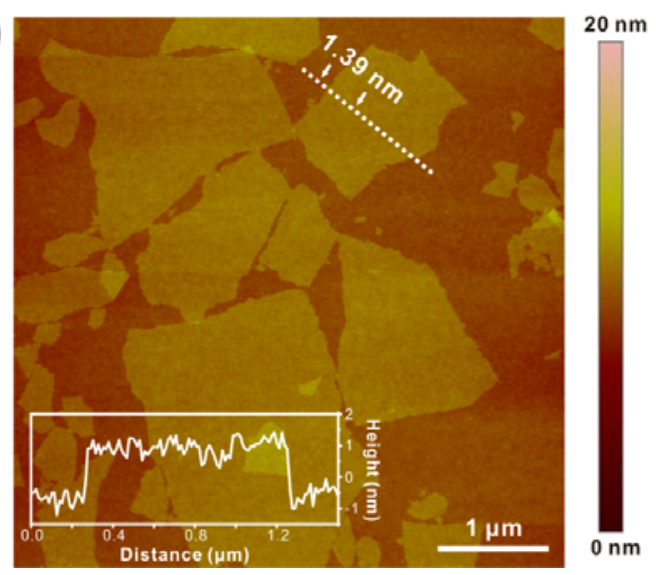

b)

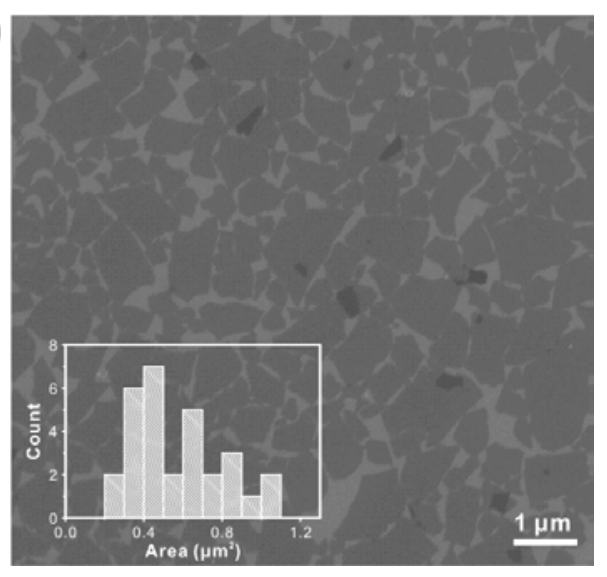

Figure S1. (a) Representative AFM image of GO nanosheets with corresponding line scan profile and (b) SEM image with a size distribution of GO nanosheets. GO suspension is mainly composed of a monolayer of graphene nanosheets with an average thickness of $1.39 \pm 0.17 \mathrm{~nm}$ and average area of $0.566 \pm 0.219 \mu \mathrm{m}^{2}$. The average values are collected with 30 samples from the AFM and SEM images.

\section{Experimental methods}

\section{A. Preparation of aqueous PANi suspension (Timing: two days)}

1) The emeraldine base form of PANi is dissolved in DMAc at $20 \mathrm{mg} \mathrm{mL}^{-1}$ by stirring the solution overnight at room temperature, and then by sonicating for $12 \mathrm{~h}$.

2) Fine particulates are then removed from the solution by filtration through a cotton filter paper (pore size: $8 \mu \mathrm{m}$ ).

3) Finally, $5.0 \mathrm{~mL}$ of the filtered PANi solution is slowly added to $45 \mathrm{~mL}$ of $\mathrm{pH}$-adjusted water ( $\mathrm{pH} 3.0)$, and the $\mathrm{pH}$ is quickly lowered to 2.5 by adding a few drops of $1.0 \mathrm{M} \mathrm{HCl}$ solution to prevent agglomeration. 
4) The obtained water-dispersive PANi suspension is filtered through a cotton filter paper again prior to use in LbL assembly.

KEY POINT: PANi suspension is typically used within two days of preparation, as they otherwise form irreversible aggregates.

\section{B. Preparation and DMAP functionalization of Au NPs (Timing: one day)}

1) A $30 \mathrm{mM}$ aqueous gold(III) chloride trihydrate $\left(\mathrm{HAuCl}_{4} \cdot 3 \mathrm{H}_{2} \mathrm{O}\right)$ solution $(30 \mathrm{~mL})$ is mixed with a $25 \mathrm{mM}$ solution of tetraoctylammonium bromide in toluene $(80 \mathrm{~mL})$ with gentle stirring.

2) A freshly prepared $0.40 \mathrm{M} \mathrm{NaBH}_{4}$ aqueous solution (25 mL) is added to the stirred mixture, which causes the immediate reduction of Au NPs.

KEY POINT: $\mathrm{NaBH}_{4}$ should be added slowly to prevent instant aggregation of the Au NPs.

3) After $1 \mathrm{~h}$, the water and toluene phases are separated using a separatory funnel and the water phase is carefully removed. The toluene phase is subsequently washed three times each with $0.10 \mathrm{M} \mathrm{H}_{2} \mathrm{SO}_{4}, 0.10 \mathrm{M} \mathrm{NaOH}$, and $\mathrm{H}_{2} \mathrm{O}$, and dried with anhydrous sodium sulfate $\left(\mathrm{Na}_{2} \mathrm{SO}_{4}\right)$ for $30 \mathrm{~min}$.

4) The resulting toluene solution is filtered through a glass fiber filter membrane to remove the remaining $\mathrm{Na}_{2} \mathrm{SO}_{4}$ powder.

5) A 0.10 M DMAP aqueous solution $(50 \mathrm{~mL})$ is added to the same amount of the asprepared mixture $(50 \mathrm{~mL})$.

6) After $1 \mathrm{~h}$, the aqueous phase is collected with a separatory funnel. As-prepared Au(+) NP suspension has a pH of ca. 11 and is highly stable, showing no noticeable aggregation even after one year. 
KEY POINT: Direct phase transfer across the organic/aqueous boundary is completed within $1 \mathrm{~h}$ without additional stirring.

\section{Calculation of relative charge density of $\mathrm{GO}(-)$ in $\mathrm{pH} 3,7$, and 11 conditions}

According to the previous report of Konkena et al. (J. Phys. Chem. Lett. 2012, 3, 867), the typical $\mathrm{p} K_{\mathrm{a}}$ values of the functional groups of $\mathrm{GO}(-)$ nanosheets are known as 4.3, 6.6, and 9.8. However, considering the difference in the preparation of the GO nanosheets, we assume their nominal $\mathrm{p} K_{\mathrm{a}}$ values in the range of 4 and 10 . Specifically, each $\mathrm{p} K_{\mathrm{a}}$ value corresponds to the ionization of different functionalities present on GO, including carboxylic acids conjugated to $\mathrm{sp}^{2}$-carbon backbone ( $\left.K_{\mathrm{a} 1} \sim 4\right)$, free carboxylic acids $\left(\mathrm{p} K_{\mathrm{a} 2} \sim 6\right)$, and phenol groups $\left(\mathrm{p} K_{\mathrm{a} 3} \sim 10\right)$. Based on these values, we could estimate the percentages of ionization of $\mathrm{GO}(-)$ nanosheets in the respective $\mathrm{pH}$ conditions tested.

$$
\begin{gathered}
\mathrm{HA}_{1} \rightleftharpoons \mathrm{A}_{1}^{-}+\mathrm{H}^{+}, K_{\mathrm{a} 1}=\frac{\left[\mathrm{A}_{1}^{-}\right]\left[\mathrm{H}^{+}\right]}{\left[\mathrm{HA}_{1}\right]} \ldots \ldots \\
\mathrm{HA}_{2} \rightleftharpoons \mathrm{A}_{2}{ }^{-}+\mathrm{H}^{+}, K_{\mathrm{a} 2}=\frac{\left[\mathrm{A}_{2}^{-}\right]\left[\mathrm{H}^{+}\right]}{\left[\mathrm{HA}_{2}\right]} \ldots \ldots \\
\mathrm{HA}_{3} \rightleftharpoons \mathrm{A}_{3}^{-}+\mathrm{H}^{+}, K_{\mathrm{a} 3}=\frac{\left[\mathrm{A}_{3}^{-}\right]\left[\mathrm{H}^{+}\right]}{\left[\mathrm{HA}_{3}\right]} \ldots \ldots \\
\mathrm{p} K_{\mathrm{a} 1}=4, \mathrm{p} K_{\mathrm{a} 2}=6, \mathrm{p} K_{\mathrm{a} 3}=10
\end{gathered}
$$

Assuming the relative population of each functional groups fraction is equivalent, according to the equation (1) at $\mathrm{pH} 3$ condition, $\frac{\left[\mathrm{A}_{1}^{-}\right]}{\left[\mathrm{HA}_{1}\right]}=10^{-1.0}=0.10$. Given the high $\mathrm{p} K_{\mathrm{a}}$ values of $\mathrm{HA}_{2}$ and 
$\mathrm{HA}_{3}$, the other functional groups are all protonated, thus, approximately $3 \%$ of the functional groups are ionized at $\mathrm{pH} 3$. In addition, at $\mathrm{pH} 7$ condition, most of $\mathrm{HA}_{1}$ are deprotonated while

$\mathrm{HA}_{3}$ are in protonated state. $\frac{\left[\mathrm{A}_{2}{ }^{-}\right]}{\left[\mathrm{HA}_{2}\right]}=10^{1.0}=10$, thus, approximately $64 \%$ of the functional groups are ionized at $\mathrm{pH}$ 7. At $\mathrm{pH} 11$ condition, both $\mathrm{HA}_{1}$ and $\mathrm{HA}_{2}$ will be deprotonated. $\frac{\left[\mathrm{A}_{3}{ }^{-}\right]}{\left[\mathrm{HA}_{3}\right]}=10^{1.0}=10$, thus, approximately $97 \%$ of the functional groups are ionized at $\mathrm{pH} 11$.

\section{Materials and equipment lists}

\section{A. Materials}

Graphite powder (Bay-Carbon SP1 grade, 325 mesh, Bay Carbon Inc., United States)

Potassium permanganate $\left(\mathrm{KMnO}_{4}\right.$, Sigma-Aldrich, United States)

Potassium persulfate, $\left(\mathrm{K}_{2} \mathrm{~S}_{2} \mathrm{O}_{8}\right.$, Sigma-Aldrich)

Phosphorus pentoxide $\left(\mathrm{P}_{2} \mathrm{O}_{5}\right.$, Sigma-Aldrich)

Ethylene diamine $\left(\mathrm{C}_{2} \mathrm{H}_{8} \mathrm{~N}_{2}\right.$, Sigma-Aldrich)

Sodium nitrate $\left(\mathrm{NaNO}_{3}\right.$, Sigma-Aldrich)

Polyaniline (PANi, Emeraldine base, M.W. 20,000, Sigma-Aldrich)

Dimethylacetamide $\left(\mathrm{C}_{4} \mathrm{H}_{9} \mathrm{NO}\right.$, DMAc, Sigma-Aldrich)

Tetraoctylammonium bromide $\left(\mathrm{C}_{32} \mathrm{H}_{68} \mathrm{NBr}\right.$, Sigma-Aldrich $)$

Gold(III) chloride trihydrate ( $\mathrm{HAuCl}_{4} \cdot 3 \mathrm{H}_{2} \mathrm{O}$, Sigma-Aldrich)

4-(dimethylamino)pyridine (DMAP, Sigma-Aldrich)

Sodium borohydride $\left(\mathrm{NaBH}_{4}\right.$, Sigma-Aldrich)

1-[3-(Dimethylamino)propyl]-3-ethylcarbodiimide methiodide (EDC, Alfa Aesar, United States) 
Concentrated sulfuric acid (98\% $\mathrm{H}_{2} \mathrm{SO}_{4}$, Daejung Chemical Co., South Korea)

Hydrochloric acid (35\% HCl, Daejung Chemical Co.)

Hydrogen peroxide (30\% $\mathrm{H}_{2} \mathrm{O}_{2}$, Daejung Chemical Co.)

Toluene $\left(\mathrm{C}_{7} \mathrm{H}_{8}\right.$, Daejung Chemical Co.)

Sodium hydroxide (NaOH, Daejung Chemical Co.)

Sodium sulfate $\left(\mathrm{Na}_{2} \mathrm{SO}_{4}\right.$, Daejung Chemical Co.)

Sodium bicarbonate ( $\mathrm{NaHCO}_{3}, \mathrm{DC}$ Chemical Co., China)

ITO coated glass $\left(4.5 \mathrm{ohm}, 1 \times 5 \mathrm{~cm}^{2}\right.$, thickness: $0.10 \mathrm{~cm}$, Asahi glass Co., Japan)

Silicon wafer ( $\mathrm{Si} / \mathrm{SiO}_{2}$, dry $\mathrm{SiO}_{2}$ thickness: $285 \mathrm{~nm}$, boron-doped p-type, resistivity: 0.01-0.02

ohm, thickness: 500-550 $\mu \mathrm{m}$, diameter: 4 in, SEHYOUNG Wafertech Co., South Korea)

Quartz glass $(1 \mathrm{~cm} \times 5 \mathrm{~cm}$, thickness: $0.10 \mathrm{~cm}$, Hanjin Quartz, South Korea)

Dialysis membrane (Spectra/Por, MWCO=12,000-14,000, Spectrum Lab. Inc., United States)

Ultrapure water (18-M $\Omega$ Milli-Q water, Merck Millipore Co., United States)

\section{B. Equipment}

Spin-dipping assisted layer-by-layer assembly device (nanoStrata Inc., United States)

Water ultrapurification system (18-M $\Omega$, Merck Millipore Co.)

Probe sonicator (VC 750, Sonics \& Materials Inc., United States)

Bath sonicator (Bransonic 3510E-DTH, Emerson Electric Co., United States)

Vacuum filtration device (Buchi, Switzerland)

Glass fiber filter membrane (pore size: $1.5 \mu \mathrm{m}$ retention, Whatman 1827-047, GE Healthcare, UK)

Cotton filter paper (pore size: $8 \mu \mathrm{m}$ retention, Whatman 1440-125, GE Healthcare) 
$\mathrm{O}_{2}$ plasma cleaner (Plasma cleaner PDC-32G, Harrick Plasma Inc., United States)

Ellipsometer (Alpha-SE, J. A. Woollam Co., United States)

UV absorbance spectroscopy (UV-1800, Dong-il Shimadzu Co., Japan)

Potentiostat (VSP300, Biologic Inc., United States)

Zetasizer nano (Nano ZS, Malvern Instruments Ltd., UK)

Field-emission scanning electron microscope (FE-SEM, Nova NanoSEM, FEI, United States)

Atomic force microscope (AFM, Veeco Instruments Inc., United States)

Surface Profiler (P-6 Stylus Profiler, KLA-Tencor Co., United States) 